Check for updates

Cite this: RSC Adv., 2019, 9, 6169

\title{
A facile synthetic route to tungsten diselenide using a new precursor containing a long alkyl chain cation for multifunctional electronic and optoelectronic applications $\uparrow$
}

\author{
Jahee Kim,,$^{\mathrm{ab}}$ Yi Rang Lim, țac Yeoheung Yoon, ${ }^{\mathrm{a}}$ Wooseok Song, (D) a Bo Keun Park, ${ }^{\text {ab }}$ \\ Jongsun Lim, (D) *a Taek-Mo Chung ${ }^{\star a b}$ and Chang Gyoun Kim ${ }^{\star a b}$
}

Single source precursors for coating and subsequent thermal decomposition processes enable a largescale, low-cost synthesis of two-dimensional transition metal dichalcogenides (TMDs). However, practical applications based on two-dimensional TMDs have been limited by the lack of applicable single source precursors for the synthesis of p-type TMDs including layered tungsten diselenide (WSe $\mathrm{W}_{2}$. We firstly demonstrate the simple and facile synthesis of $\mathrm{WSe}_{2}$ layers using a newly developed precursor that allows improved dispersibility and lower decomposition temperature. We study the thermal decomposition mechanism of three types of $\left(\mathrm{Cat}^{+}\right)_{2}\left[\mathrm{WSe}_{4}\right]$ precursors to assess the most suitable precursor for the synthesis of $\mathrm{WSe}_{2}$ layers. The resulting chemical and structural exploration of solutionprocessed $\mathrm{WSe}_{2}$ layers suggests that the $(\mathrm{CTA})_{2}\left[\mathrm{WSe}_{4}\right]$ may be a promising precursor because it resulted in the formation of high-crystalline $\mathrm{WSe}_{2}$. In addition, this study verifies the capability of $\mathrm{WSe}_{2}$ layers for multifunctional applications in optoelectronic and electronic devices. The photocurrent of $\mathrm{WSe}_{2}$-based photodetectors shows an abrupt switching behavior under periodic illumination of visible or IR light. The extracted photoresponsivity values for $\mathrm{WSe}_{2}$-based photodetectors recorded at $0.5 \mathrm{~V}$ correspond to 26.3 $\mathrm{mA} \mathrm{W} \mathrm{W}^{-1}$ for visible light and $5.4 \mathrm{~mA} \mathrm{~W}^{-1}$ for IR light. The WSe $\mathrm{W}_{2}$-based field effect transistors exhibit unipolar $\mathrm{p}$-channel transistor behavior with a carrier mobility of $0.45 \mathrm{~cm}^{2} \mathrm{~V}^{-1} \mathrm{~s}^{-1}$ and an on-off ratio of $\sim 10$.

Received 3rd January 2019
Accepted 10th February 2019

DOI: 10.1039/c9ra00041k

rsc.li/rsc-advances route in large-scale TMDs with spatial homogeneity. The largescale TMDs need to be compatible with top-down lithographic fabrication processes, so they can realize device arrays with the same response. Thus far, early approaches, including mechanical and chemical exfoliation and chemical vapor deposition (CVD), have been implemented to produce atomically thin TMDs. ${ }^{10-13}$ However, these strategies are technically hindered for industrial applications due to their inability to synthesize large-area TMD films. To resolve this deficiency, an alternative synthetic route was suggested: the synthesis of molybdenum disulfides $\left(\mathrm{MoS}_{2}\right)$, as the representative member of TMDs, was performed using well-designed two-step thermal decomposition processes of a $\left(\mathrm{NH}_{4}\right)_{2} \mathrm{MoS}_{4}$ single source precursor, thereby facilitating a simple, large-scale, and low-cost growth of $\mathrm{MoS}_{2}$ layers that could be easily applied to plastic substrates. ${ }^{14,15}$ Also, previous attempts achieved a facile synthesis of threedimensional binary and ternary TMD nanostructures by solvothermal routes. ${ }^{16-19}$ Unfortunately, it is widely recognized that the bottleneck of 2D TMDs in terms of their solution-processed growth is the lack of applicable and commercially-available single source precursors for the synthesis of p-type TMDs including layered tungsten diselenides $\left(\mathrm{WSe}_{2}\right)$. $\mathrm{WSe}_{2}$ is one of few p-type TMDs and has high carrier mobility, which is
Technology, Daejeon 305-600, Republic of Korea.E-mail: jslim@krict.re.kr

${ }^{b}$ Department of Advanced Materials and Chemical Engineering, University of Science and Technology (UST), 217 Gajeong-ro, Yuseong-gu, Daejeon 34113, Republic of Korea ${ }^{c}$ School of Electrical and Electronic Engineering, Yonsei University, 50 Yonsei-ro, Seodaemun-gu, Seoul 03722, Republic of Korea

$\dagger$ Electronic supplementary information (ESI) available: Data of TG-DTA-Mass spectroscopy. See DOI: $10.1039 / \mathrm{c} 9 \mathrm{ra00041 \textrm {k }}$

\$ These authors contributed equally to this work. 
a prerequisite for applications in complementary logic circuits, gas sensors, and optoelectronics, because most of the TMDs have n-type semiconducting behavior. ${ }^{20}$ Although $\mathrm{MoTe}_{2}$ possesses p-type semiconducting conduction, this material is unstable in ambient conditions owing to a relatively small cohesive energy $(12.01 \mathrm{eV}) .{ }^{21}$ For the first time, we report the simple and facile synthesis of $\mathrm{WSe}_{2}$ layers using a newly developed precursor that gives improved dispersibility and lower decomposition temperature. In previous studies, $\left(\mathrm{Cat}^{+}\right)_{2}\left[\mathrm{WSe}_{4}\right]$ complexes containing $\left(\mathrm{Ph}_{4} \mathrm{P}\right)_{2}\left[\mathrm{WSe}_{4}\right]$ and $\left(\mathrm{Et}_{4}{ }^{-}\right.$ $\mathrm{N})_{2}\left[\mathrm{WSe}_{4}\right]$ were synthesized. ${ }^{22,23}$ Notably, there are crucial issues for adopting single source precursors to synthesize $\mathrm{WSe}_{2}$ layers: (i) "dispersibility" in organic solvents and (ii) "low decomposition temperature" are strictly necessary because the solution containing the precursors can be uniformly coated on desired substrates for the formation of atomically thin $\mathrm{WSe}_{2}$ layers and the low synthetic temperature allows the direct application to plastic substrates. We rationally designed an unprecedented precursor, $(\mathrm{CTA})_{2}\left[\mathrm{WSe}_{4}\right]$ with a long alkyl chain of cetyltrimethylammonium, for the synthesis of $\mathrm{WSe}_{2}$ layers to improve the dispersibility and decrease the decomposition temperature. To assess the most suitable precursor for the synthesis of $\mathrm{WSe}_{2}$ layers, we systematically explored the decomposition mechanism of newly developed (CTA $)_{2}\left[\mathrm{WSe}_{4}\right]$, $\left(\mathrm{Ph}_{4} \mathrm{P}\right)_{2}\left[\mathrm{WSe}_{4}\right]$, and $\left(\mathrm{Et}_{4} \mathrm{~N}\right)_{2}\left[\mathrm{WSe}_{4}\right]$ and implemented the presynthesis of $\mathrm{WSe}_{2}$ nanoparticles (NPs) using the three types of precursors via thermal decomposition of $\left(\mathrm{Cat}^{+}\right)_{2}\left[\mathrm{WSe}_{4}\right]$ with oleylamine as a capping ligand.

\section{Experimental section}

\section{Synthesis of $\mathrm{Na}_{2} \mathrm{Se}_{4}$}

A solid mixture of $\mathrm{Na}(0.25 \mathrm{~g}, 10 \mathrm{mmol})$ and $\mathrm{Se}(1.58 \mathrm{~g}, 20 \mathrm{mmol})$ was placed in a $100 \mathrm{~mL}$ side-armed flask equipped with a magnetic spin bar. The flask was also equipped with a bubbler that was charged with $30 \mathrm{~mL}$ of liquid ammonia in a dry ice/ acetone bath $\left(-78{ }^{\circ} \mathrm{C}\right)$. The reaction mixture was stirred from $-72{ }^{\circ} \mathrm{C}$ to room temperature to produce dry $\mathrm{Na}_{2} \mathrm{Se}_{4}$ under an inert atmosphere.

\section{Synthesis of $\left(\mathrm{Ph}_{4} \mathrm{P}\right)_{2}\left[\mathrm{WSe}_{4}\right]$ and $\left(\mathrm{Et}_{4} \mathbf{N}\right)_{2}\left[\mathrm{WSe}_{4}\right]$}

$\left(\mathrm{Ph}_{4} \mathrm{P}\right)_{2}\left[\mathrm{WSe}_{4}\right]$ and $\left(\mathrm{Et}_{4} \mathrm{~N}\right)_{2}\left[\mathrm{WSe}_{4}\right]$ were prepared by modifying the previously established methods. ${ }^{\mathbf{1 8 , 1 9}}\left(\mathrm{Ph}_{4} \mathrm{P}\right)_{2}\left[\mathrm{WSe}_{4}\right]$ and $\left(\mathrm{Et}_{4} \mathrm{~N}\right)_{2}\left[\mathrm{WSe}_{4}\right]$ were both synthesized in the same way. A solid mixture of $\mathrm{Na}_{2} \mathrm{Se}_{4}(1.83 \mathrm{~g}, 5 \mathrm{mmol})$ and $\mathrm{W}(\mathrm{CO})_{6}(1.76 \mathrm{~g}, 5 \mathrm{mmol})$ was placed into a $100 \mathrm{~mL}$ flask equipped with a cooling condenser. The reaction mixture was dissolved in $40 \mathrm{~mL}$ of $\mathrm{N}, \mathrm{N}$ dimethylformamide (DMF) and stirred at $90{ }^{\circ} \mathrm{C}$ for $60 \mathrm{~min}$. After cooling to $70{ }^{\circ} \mathrm{C}, \mathrm{Ph}_{4} \mathrm{PCl}(3.74 \mathrm{~g}, 10 \mathrm{mmol})$ or $\mathrm{Et}_{4} \mathrm{NCl}(1.66 \mathrm{~g}, 10$ $\mathrm{mmol})$ was added to the solution and the reaction was cooled down to room temperature with stirring for $30 \mathrm{~min}$. The mixture was filtered to remove by-products, mainly $\mathrm{NaCl}$. The filtrate was added $40 \mathrm{~mL}$ of tetrahydrofuran (THF) and the flask was placed in the freezer $\left(-30{ }^{\circ} \mathrm{C}\right)$ for $24 \mathrm{~h}$ to grow a red colored crystalline solid for $\left(\mathrm{Ph}_{4} \mathrm{P}\right)_{2}\left[\mathrm{WSe}_{4}\right](2.20 \mathrm{~g}, 37 \%)$. Calcd for $\mathrm{C}_{48} \mathrm{H}_{40} \mathrm{P}_{2} \mathrm{Se}_{4} \mathrm{~W}$ (1178.46): C, 48.9; H, 3.42. Found: C, 48.4; H,
3.40. IR ( $\left.\mathrm{cm}^{-1}\right): 3045,3002,754,723,689,526,300$. In addition, red crystalline solid $(0.80 \mathrm{~g}, 21 \%)$ for $\left(\mathrm{Et}_{4} \mathrm{~N}\right)_{2}\left[\mathrm{WSe}_{4}\right]$ was collected at the bottom of the flask. Calcd for $\mathrm{C}_{16} \mathrm{H}_{40} \mathrm{~N}_{2} \mathrm{Se}_{4} \mathrm{~W}$ (760.18): C, 25.3; H, 5.30; N, 3.69. Found: C, 24.9; H, 5.10; N, 3.8. IR $\left(\mathrm{cm}^{-1}\right): 2974,2920,1440.47,300$.

\section{Synthesis of (CTA $)_{2}\left[\mathrm{WSe}_{4}\right]$}

A solid mixture of $\mathrm{Na}_{2} \mathrm{Se}_{4}(1.83 \mathrm{~g}, 5 \mathrm{mmol})$ and $\mathrm{W}(\mathrm{CO})_{6}(1.76 \mathrm{~g}, 5$ mmol) was placed in a $125 \mathrm{~mL}$ flask equipped with a cooling condenser. The reaction mixture was dissolved in $40 \mathrm{~mL}$ of DMF and allowed to stir at $90{ }^{\circ} \mathrm{C}$ for $60 \mathrm{~min}$. After the mixture was cooled to $70{ }^{\circ} \mathrm{C}$, cetyltrimethylammonium chloride $(3.20 \mathrm{~g}, 10$ $\mathrm{mmol}$ ) was added to the solution followed by cooling down to room temperature with stirring for $30 \mathrm{~min}$. The mixture was filtered to remove by-products, mainly $\mathrm{NaCl}$. The filtrate was added to the excess amount of diethyl ether to precipitate. The precipitate was dissolved in THF and filtered, and the solvent was then removed under reduced pressure. A red crystalline solid $(2.00 \mathrm{~g}, 37 \%)$ was eventually collected at the bottom of the flask. Calcd for $\mathrm{C}_{38} \mathrm{H}_{84} \mathrm{~N}_{2} \mathrm{Se}_{4} \mathrm{~W}$ (1068.77): C, 42.7; H, 7.92; N, 2.62. Found: C, 42.5; H, 7.90; N, 2.80. IR ( $\left.\mathrm{cm}^{-1}\right)$ : 3000, 2919, 2850, 1468, 301 .

\section{Solvothermal decomposition of $\left(\mathrm{Cat}^{+}\right)_{2}\left[\mathrm{WSe}_{4}\right]$}

A mixture of oleylamine $(50 \mathrm{~mL})$ and $\left(\mathrm{Cat}^{+}\right)_{2}\left[\mathrm{WSe}_{4}\right](0.5 \mathrm{~g})$ were placed in a $100 \mathrm{~mL}$ flask equipped with a cooling condenser connected with bubbler. The reaction mixture was allowed to stir at $300{ }^{\circ} \mathrm{C}$ for $12 \mathrm{~h}$ under an inert atmosphere. The resultant was cooled down to room temperature and the excess amount of toluene was added. Then, the mixture was centrifuged to obtain $\mathrm{WSe}_{2}$ nanoparticles and washed three times with toluene to remove free oleylamine.

\section{Results and discussion}

We synthesized the $\left(\mathrm{Ph}_{4} \mathrm{P}\right)_{2}\left[\mathrm{WSe}_{4}\right]$ and $\left(\mathrm{Et}_{4} \mathrm{~N}\right)_{2}\left[\mathrm{WSe}_{4}\right]$ precursors by modifying previously established methods, as depicted in Fig. $1 \mathrm{a}$ and $\mathrm{b}^{22}$ In the previous methods, $\mathrm{K}_{2} \mathrm{Se}_{3}$ was used as a starting material, whereas we adopted $\mathrm{Na}_{2} \mathrm{Se}_{4}$ as selenide source for reacting with the $\mathrm{W}(\mathrm{CO})_{6} \cdot{ }^{23}$ In addition, we used $\left(\mathrm{Ph}_{4} \mathrm{P}\right) \mathrm{Cl}$ and $\left(\mathrm{Et}_{4} \mathrm{~N}\right) \mathrm{Cl}$, which both contain $\mathrm{Cl}^{-}$anions to capture for $\mathrm{Na}^{+}$cations in as-synthesized $\mathrm{Na}_{2} \mathrm{WSe}_{4}$. Based on hard-hard and soft-soft interaction mechanism, it preferably forms $\mathrm{NaCl}$ as a by-product when a compound having a $\mathrm{Cl}^{-}$ anion is used rather than a compound having a $\mathrm{Br}^{-}$anion, such as $\left(\mathrm{Ph}_{4} \mathrm{P}\right) \mathrm{Cl}$ and $\left(\mathrm{Et}_{4} \mathrm{~N}\right) \mathrm{Cl}$. Furthermore, when we used $\mathrm{K}_{2} \mathrm{Se}_{3}$ as a starting material, a $\mathrm{K}_{2} \mathrm{Se}_{2}$ by-product was inevitably formed, and it was difficult to separate it from the resultants for obtaining the pure products because it did not easily dissolve in organic solvents. In order to obtain purer products, we carefully utilized recrystallization using the $\mathrm{Na}_{2} \mathrm{Se}_{4}$. The reaction mechanism of the precursors for $\mathrm{WSe}_{2}$ is as follows:

$$
\begin{gathered}
\mathrm{Na}+2 \mathrm{Se} \rightarrow \mathrm{Na}_{2} \mathrm{Se}_{4} \\
\mathrm{~W}(\mathrm{CO})_{6}+\mathrm{Na}_{2} \mathrm{Se}_{4} \rightarrow \mathrm{Na}_{2}\left[\mathrm{WSe}_{4}\right]+6 \mathrm{CO} \uparrow
\end{gathered}
$$



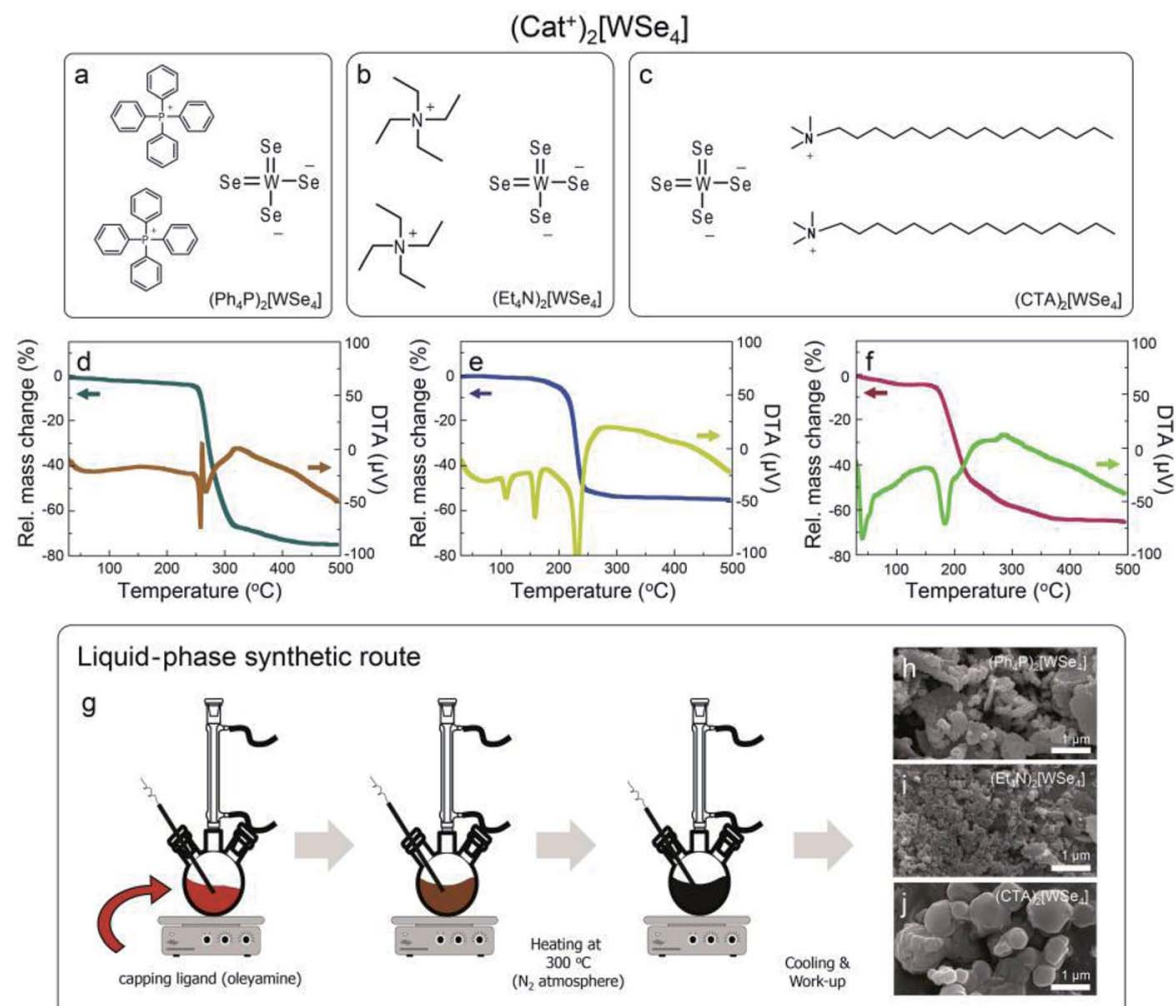

Fig. 1 Cationic tungsten selenide complexes, $\left(\mathrm{Cat}^{+}\right)_{2}\left[\mathrm{WSe} \mathrm{e}_{4}\right]$, (a) $\left(\mathrm{Ph}_{4} \mathrm{P}\right)_{2}\left[\mathrm{WSe} \mathrm{e}_{4}\right]$, (b) $\left(\mathrm{Et}_{4} \mathrm{~N}\right)_{2}\left[\mathrm{WSe} \mathrm{e}_{4}\right]$, and (c) (CTA) ${ }_{2}\left[\mathrm{WSe} \mathrm{e}_{4}\right]$, (d-f) TG-DTA curves for the all tungsten selenide complexes. (g) Schematic diagram of solvothermal synthesis of $\mathrm{WSe}_{2} \mathrm{NPs}_{\mathrm{s}}$ in solution phase using the all complexes at $300{ }^{\circ} \mathrm{C}$ and $(\mathrm{h}-\mathrm{j})$ their morphological features measured by SEM.

$$
\begin{array}{r}
\mathrm{Na}_{2}\left[\mathrm{WSe}_{4}\right]+2\left(\mathrm{Cat}^{+}\right) \mathrm{Cl} \rightarrow\left(\mathrm{Cat}^{+}\right)_{2}\left[\mathrm{WSe}_{4}\right]+2 \mathrm{NaCl} \\
\left({ }^{*}\left(\mathrm{Cat}^{+}\right): \mathrm{Ph}_{4} \mathrm{P}^{+}, \mathrm{Et}_{4} \mathrm{~N}^{+}, \text {and } \mathrm{CTA}^{+}\right)
\end{array}
$$

Based on this mechanism, we synthesized unprecedented $(\mathrm{CTA})_{2}\left[\mathrm{WSe}_{4}\right]$ using cetyltrimethylammonium salts $\left(\mathrm{CTA}^{+}\right)$with long alkyl groups as a precursor for the solution-processable synthesis of $\mathrm{WSe}_{2}$, as seen in Fig. 1c. Unlike the two wellknown precursors, it possesses long alkyl groups, which makes it possible to obtain high solubility in various organic solvents. Thus, it seems to be suitable as a precursor for the solution-based synthetic processes. For the synthesis of $\mathrm{WSe}_{2}$ through the basis of thermal properties of the three compounds, thermogravimetric-differential thermal analysismass spectroscopic analysis (TG-DTA-Mass) was performed to understand the synthetic mechanism for $\mathrm{WSe}_{2}$ (Fig. 1d-f). We examined thermal behaviors for all the samples from room temperature to $500{ }^{\circ} \mathrm{C}$. First, $\left(\mathrm{Ph}_{4} \mathrm{P}\right)_{2}\left[\mathrm{WSe}_{4}\right]$ was decomposed in the range of $260.4-270.6^{\circ} \mathrm{C}$, and it was clearly confirmed by the result of DTA that melting and decomposition of the compound occurs in this temperature region, as shown in Fig. 1d. The mass intensity at the region appears at 78 and $234 \mathrm{~m} / \mathrm{z}$, which correspond to the molecular weights for selenium and diphenyl selenide, respectively (Fig. S1 $\dagger$ ). We referred to mass spectrum of National Institute of Standards and Technology (NIST). The mass spectra of diphenyl diselenide showed 78 and $234 \mathrm{~m} / \mathrm{z}$ exhibiting a similar isotope peaks. Furthermore, the residue was found to be $25 \%$ at about $500{ }^{\circ} \mathrm{C}$, which was similar to the ratio of $\mathrm{WSe}_{2}(29 \%)$ in total molecular weight. A TGA curve of $\left(\mathrm{Et}_{4} \mathrm{~N}\right)_{2}\left[\mathrm{WSe}_{4}\right]$ showed endothermic peaks at 108 and $158{ }^{\circ} \mathrm{C}$, and it was completely melted with decomposition at between $234.8^{\circ} \mathrm{C}$ and $239.5^{\circ} \mathrm{C}$, as shown in Fig. 1e. The mass intensity appears at 101 and $218 \mathrm{~m} / \mathrm{z}$ corresponding to the molecular weight of triethylamine and diethyl diselenide, respectively (Fig. S2 $\dagger$ ). The mass spectra of trimethylamine showed a same isotope peaks. In addition, the residue at $500{ }^{\circ} \mathrm{C}$ in the TGA result was estimated to be $45 \%$, which corresponds to the ratio of $\mathrm{WSe}_{2}$ in total molecular weight. In case of $(\mathrm{CTA})_{2}\left[\mathrm{WSe}_{4}\right]$, it showed endothermic peak at $40{ }^{\circ} \mathrm{C}$ and completely melted and decomposed at the temperature range of $183.8-196.0^{\circ} \mathrm{C}$, which is the lowest temperature comparing with the other two precursors, as displayed in Fig. 1f. The mass intensity appeared at $190 \mathrm{~m} / \mathrm{z}$, which coincided with the major peak of mass spectrum of dimethyl diselenide. However, the mass intensity observed at below $110 \mathrm{~m} / z$ could not be unambiguously confirmed. Because of the long alkyl groups of $(\mathrm{CTA})_{2}\left[\mathrm{WSe}_{4}\right]$, a variety of decomposition products could not be completely identified. Thus, it was considered that it was decomposed into several short alkyl chains at below than $110 \mathrm{~m} / \mathrm{z}$. The peak observed at $58 \mathrm{~m} / \mathrm{z}$ in TG-DTA-Mass resulted from the major peak of cetyl dimethylamine. This was monitored mainly by the photoionization (PI) mode of the mass spectrometer with an weak energy intensity $(10.2 \mathrm{eV})$ (Fig. S3†). The residue of $(\mathrm{CTA})_{2}\left[\mathrm{WSe}_{4}\right]$ at $500{ }^{\circ} \mathrm{C}$ was $34 \%$, which is similar to the ratio of 
$\mathrm{WSe}_{2}$ in the total molecular weight $(32 \%)$. Based on these results of the TG-DTA-Mass analysis, the mechanism of $\mathrm{WSe}_{2}$ synthesis from $\left(\mathrm{Cat}^{+}\right)_{2}\left[\mathrm{WSe}_{4}\right]$ could be summarized as follows:

$$
\begin{gathered}
\left(\mathrm{Ph}_{4} \mathrm{P}\right)_{2}\left[\mathrm{WSe}_{4}\right] \rightarrow 2 \mathrm{Ph}_{3} \mathrm{P}+\mathrm{Ph}-\mathrm{Se}-\mathrm{Se}-\mathrm{Ph}+\mathrm{WSe}_{2} \\
\left(\mathrm{Et}_{4} \mathrm{~N}\right)_{2}\left[\mathrm{WSe}_{4}\right] \rightarrow 2 \mathrm{Et}_{3} \mathrm{~N}+\mathrm{Et}-\mathrm{Se}-\mathrm{Se}-\mathrm{Et}+\mathrm{WSe}_{2}
\end{gathered}
$$

$(\mathrm{CTA})_{2}\left[\mathrm{WSe}_{4}\right] \rightarrow 2($ cetyl $)(\mathrm{Me})_{2} \mathrm{~N}+\mathrm{Me}-\mathrm{Se}-\mathrm{Se}-\mathrm{Me}+\mathrm{WSe}_{2}(6)$

The mechanism of thermal decomposition for all the samples is described in eqn (4) to (6). Based on these results, we preliminarily synthesized $\mathrm{WSe}_{2}$ NPs by direct pyrolysis of $\left(\mathrm{Cat}^{+}\right)_{2}\left[\mathrm{WSe}_{4}\right]$ precursors in solution to assess the most suitable precursor for the synthesis of $\mathrm{WSe}_{2}$ layers, as shown in Fig. 1g. Oleylamine is typically employed as a solvent and also acts as a capping ligand to prevent the aggregation of materials. ${ }^{24}$ In general, the use of specific surface capping ligands is the most important factor in producing thickness-controlled TMDs. ${ }^{25}$ Furthermore, the redox reaction occurs easily to form $\mathrm{WSe}_{2}$, since the electrons in $\left(\mathrm{Cat}^{+}\right)_{2}\left[\mathrm{WSe}_{4}\right]$ easily migrate between $\mathrm{W}$ and Se without the addition of an external reducing agent. ${ }^{26}$ The synthesis of $\mathrm{WSe}_{2}$ with oleylamine was implemented at $300{ }^{\circ} \mathrm{C}$ for $12 \mathrm{~h}$. Fig. 1h-j showed representative scanning electron microscopy (SEM) images of $\mathrm{WSe}_{2}$ synthesized using $\left(\mathrm{Ph}_{4} \mathrm{P}\right)_{2^{-}}$ $\mathrm{WSe}_{4},\left(\mathrm{Et}_{4} \mathrm{~N}\right)_{2}\left[\mathrm{WSe}_{4}\right]$ and $(\mathrm{CTA})_{2}\left[\mathrm{WSe}_{4}\right]$ precursors. In the rationally-designed $(\mathrm{CTA})_{2}\left[\mathrm{WSe}_{4}\right]$ precursor, uniform and larger particles were observed unambiguously. First, we compared the chemical and structural features of $\mathrm{WSe}_{2}$ NPs pre-synthesized using the three types of $\left(\mathrm{Cat}^{+}\right)_{2}\left[\mathrm{WSe}_{4}\right]$ precursors $\left(\left(\mathrm{Ph}_{4} \mathrm{P}\right)_{2}[-\right.$ $\left.\mathrm{WSe}_{4}\right],\left(\mathrm{Et}_{4} \mathrm{~N}\right)_{2}\left[\mathrm{WSe}_{4}\right]$, and $\left.(\mathrm{CTA})_{2}\left[\mathrm{WSe}_{4}\right]\right)$. The chemical identification of $\mathrm{WSe}_{2}$ NPs synthesized by a solvothermal synthetic route was conducted using X-ray photoelectron spectroscopy (XPS). XPS spectra were acquired with a normal emission geometry using conventional monochromatic $\mathrm{Al} \mathrm{K} \alpha$ radiation $(h \nu=1486.6 \mathrm{eV})$. Each spectrum was fitted with a GaussianLorentzian function. The XPS $\mathrm{W}$ 4f and Se $3 \mathrm{~d}$ core level spectra extracted from the as-synthesized $\mathrm{WSe}_{2} \mathrm{NPs}$ using $\left(\mathrm{Ph}_{4} \mathrm{P}\right)_{2}[-$ $\left.\mathrm{WSe}_{4}\right]$ and after post-annealing at 500 and $600{ }^{\circ} \mathrm{C}$, respectively, are displayed in Fig. 2a-f. Fig. 2a, c, and e reveal that the $\mathrm{W} 4 \mathrm{f}_{7 / 2}$ and $\mathrm{W} 4 \mathrm{f}_{5 / 2}$ doublet peaks corresponding to $\mathrm{WSe}_{2}$ appear at binding energies $\left(E_{\mathrm{B}}\right)$ of 32.4 and $34.6 \mathrm{eV}$, respectively. The $\mathrm{WSe}_{3}$-related bonding states $\left(E_{\mathrm{B}}=33.2\right.$ and $\left.35.4 \mathrm{eV}\right), \mathrm{WO}_{3}$ related states $\left(E_{\mathrm{B}}=36.1\right.$ and $\left.38.3 \mathrm{eV}\right)$, and $\mathrm{W} 5 \mathrm{p}_{2 / 3}\left(E_{\mathrm{B}}=37.5 \mathrm{eV}\right)$ are observed simultaneously. With adopting post-annealing and increasing the temperature, the intensity of $\mathrm{WSe}_{3}$ peaks decreased markedly, presumably owing to the heat-driven deselenization process. $\mathrm{WO}_{3}$-related peaks is originated from the fact that the sample was easily oxidized when it was exposed to ambient conditions because of their low cohesive energy $(15.45 \mathrm{eV})$ induced by a small difference in electronegativity between $\mathrm{W}$ and Se. However, the oxidation was effectively inhibited due to their high crystallinity. Fig. 2b, d, and f display the Se $3 \mathrm{~d}$ core level spectra for $\mathrm{WSe}_{2}$ NPs before and after postannealing, indicating that the intensity of $\mathrm{WSe}_{3}$-related bonding states $\left(E_{\mathrm{B}}=\mathbf{5 4 . 1}\right.$ and $\left.54.9 \mathrm{eV}\right)$ and Se-C bonding states $\left(E_{\mathrm{B}}=55.4\right.$ and $\left.56.2 \mathrm{eV}\right)$ decreased, whereas the $\mathrm{WSe}_{2}$-related peaks $\left(E_{\mathrm{B}}=54.7\right.$ and $\left.55.5 \mathrm{eV}\right)$ were predominantly observed with increasing post-annealing temperature, which is in agreement with the $\mathrm{W}$ 4f core level spectra. The temperature evolution of $\mathrm{W} 4 \mathrm{f}$ and Se $3 \mathrm{~d}$ core level spectra obtained from the $\mathrm{WSe}_{2}$ NPs using $\left(\mathrm{Et}_{4} \mathrm{~N}\right)_{2}\left[\mathrm{WSe}_{4}\right]$ and $(\mathrm{CTA})_{2} \mathrm{WSe}_{4}$ precursors seemed to follow a similar trend, as displayed in Fig. $2 \mathrm{~g}-\mathrm{r}$. However, it should be noted that $\mathrm{WO}_{3}$-related and $\mathrm{WSe}_{3}$-related peaks disappeared completely in the $\mathrm{W} 4 \mathrm{f}$ core level spectra for $\mathrm{WSe}_{2}$ NPs synthesized using (CTA $)_{2} \mathrm{WSe}_{4}$, which reflects its effective deselenization and crystallization presumably due to its lower decomposition temperature. To evaluate the crystallinity of $\mathrm{WSe}_{2}$ NPs synthesized by the three types of precursors, Raman spectroscopy analysis was implemented, as shown in Fig. 2s-u. The Raman spectra were recorded at an excitation wavelength of $514 \mathrm{~nm}$. Generally, degenerated $\mathrm{E}_{2 \mathrm{~g}}$ (in-plane vibration) and $\mathrm{A}_{1 \mathrm{~g}}$ (out-of-plane vibration) phonon modes reflected the existence of high-crystalline $\mathrm{WSe}_{2} \cdot{ }^{27}$ However, the two phonon modes are absent for $\mathrm{WSe}_{2}$ NPs synthesized using the $\left(\mathrm{Ph}_{4} \mathrm{P}\right)_{2}\left[\mathrm{WSe}_{4}\right]$ precursor before post-annealing, whereas the broad peak at $\sim 250 \mathrm{~cm}^{-1}$ is observed after the post-annealing at $500{ }^{\circ} \mathrm{C}$ and the intensity of the peak becomes higher with increasing post-annealing temperature. Conversely, there are degenerated $\mathrm{A}_{1 \mathrm{~g}}$ and $\mathrm{E}_{2 \mathrm{~g}}$ phonon modes of the $\mathrm{WSe}_{2}$ NPS synthesized using $\left(\mathrm{Et}_{4} \mathrm{~N}\right)_{2}\left[\mathrm{WSe}_{4}\right]$ and $(\mathrm{CTA})_{2}\left[\mathrm{WSe}_{4}\right]$, regardless of the adoption of post-annealing. Astonishingly, the full widths at half maximum (FWHM) of the two phonon modes of $\mathrm{WSe}_{2}$ using (CTA $)_{2}\left[\mathrm{WSe}_{4}\right]$ decreased unambiguously. This finding suggests that $(\mathrm{CTA})_{2}\left[\mathrm{WSe}_{4}\right]$ is a promising precursor because it yields the synthesis of high-crystalline $\mathrm{WSe}_{2}$. We carefully developed the optimal precursor for synthesis of the $\mathrm{WSe}_{2}$ layer through preliminary studies of chemical and structural features of $\mathrm{WSe}_{2}$ NPs using the three types of $\left(\mathrm{Cat}^{+}\right)_{2}\left[\mathrm{WSe}_{4}\right]$ precursors. To synthesize $\mathrm{WSe}_{2}$ layers, a $0.5 \mathrm{wt} \%(\mathrm{CTA})_{2}\left[\mathrm{WSe}_{4}\right]$ single source precursor was stirred in DMF at room temperature for $60 \mathrm{~min}$, as displayed in Fig. 3a. The precursor solution was then dropcasted onto $\mathrm{SiO}_{2}(300 \mathrm{~nm}) / \mathrm{Si}(001)$ substrates with UVstimulated hydrophilic treatment. After the drop-casting of the precursor solution, the samples were immediately annealed at $100{ }^{\circ} \mathrm{C}$ for $1 \mathrm{~min}$ to remove the solvent. During this procedure, the few-layered lamellar structure of $(\mathrm{CTA})_{2}\left[\mathrm{WSe}_{4}\right]$ is formed in the surface of $\mathrm{SiO}_{2}$ substrate. The formation of lamella structure on the surface can be mediated by the electrostatic attraction between $(\mathrm{CTA})_{2}\left[\mathrm{WSe}_{4}\right]$ and $\mathrm{SiO}_{2}$. In addition, chemical identification of the as-formed lamellar structure on $\mathrm{SiO}_{2}$ was implemented by XPS, reflecting that the as-coated precursor was well-maintained under atmospheric conditions (Fig. S4†). The samples were located into the furnace, after which a two-step thermal decomposition process for the synthesis of $\mathrm{WSe}_{2}$ layers was implemented at $300{ }^{\circ} \mathrm{C}\left(1^{\text {st }} \mathrm{Step}\right)$ by introducing $\mathrm{Ar}(450 \mathrm{sccm})$ for $30 \mathrm{~min}$ and subsequently annealed at $600{ }^{\circ} \mathrm{C}\left(2^{\text {nd }}\right.$ Step) under $450 \mathrm{sccm}$ flow of $\mathrm{Ar}$ at a pressure of 3.5 torr for $30 \mathrm{~min}$. These synthetic conditions were based on the optimized synthetic parameters for $\mathrm{WSe}_{2}$ NPs. The surface morphology of the $\mathrm{WSe}_{2}$ layers was confirmed by optical microscopy, as seen in Fig. $3 \mathrm{~b}$ and c. Raman mapping was conducted to evaluate the uniformity of the $\mathrm{WSe}_{2}$ layers, as seen in Fig. 3d, with the result that $I_{\mathrm{E}_{2 g}+\mathrm{A}_{1 g}}$ exhibited excellent 

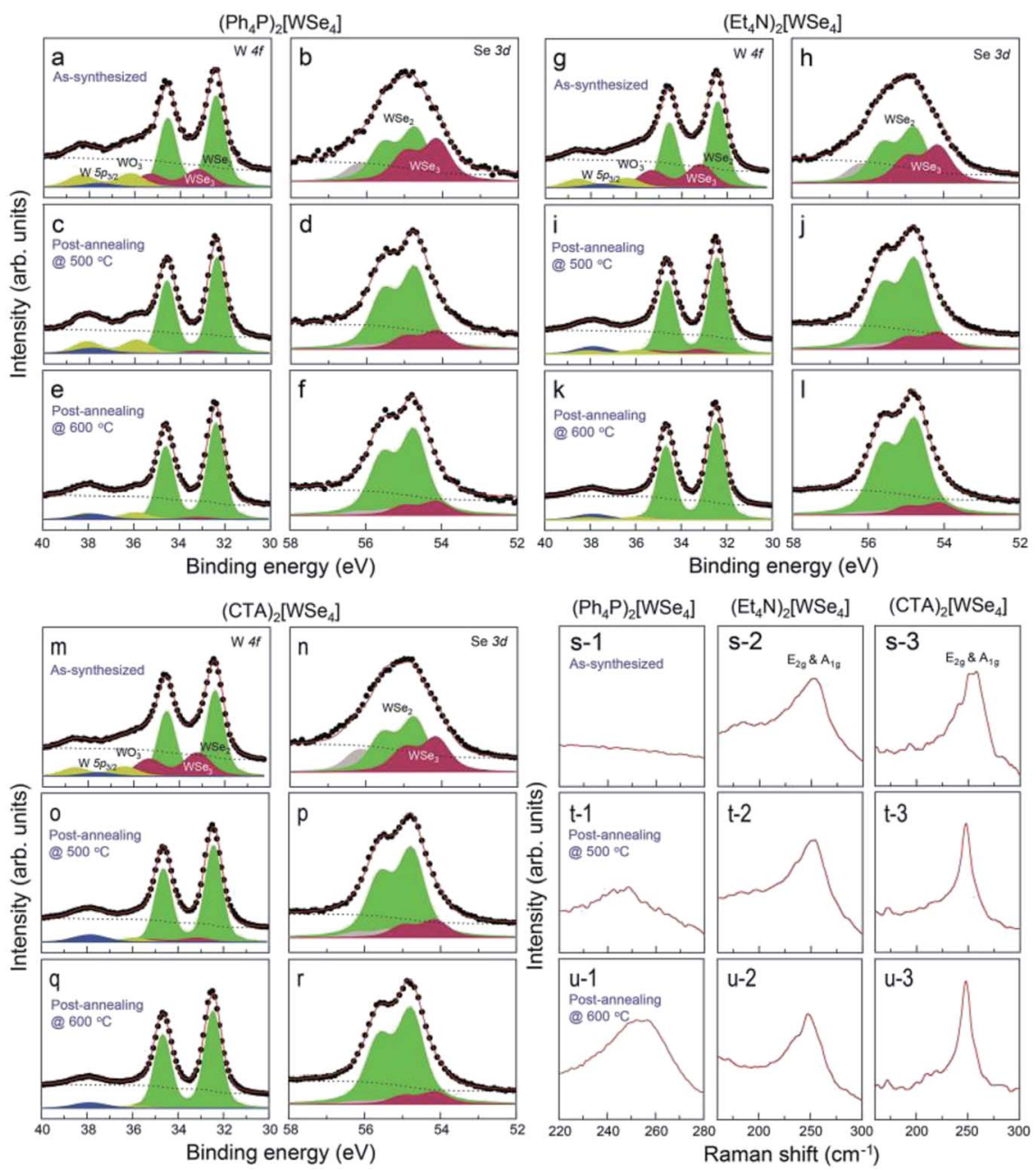

Fig. 2 XPS W $4 f$ and Se $3 d$ core level spectra for WSe 2 NPs grown by a solvothermal synthetic route using $(a-f)\left(\mathrm{Ph}_{4} P\right)_{2}\left[W S e_{4}\right],(g-l)\left(E_{4} N\right)_{2}\left[W S e_{4}\right]$, $(\mathrm{m}-\mathrm{r})(\mathrm{CTA})_{2}\left[\mathrm{WSe}_{4}\right]$ before and after post-annealing at $500{ }^{\circ} \mathrm{C}$ and $600{ }^{\circ} \mathrm{C}$. Representative Raman spectra with an excitation wavelength of $514 \mathrm{~nm}$ of $\mathrm{WSe}_{2}$ NPs using $(\mathrm{s}-1, \mathrm{t}-1, \mathrm{u}-1)\left(\mathrm{Ph}_{4} \mathrm{P}\right)_{2}\left[\mathrm{WSe} \mathrm{H}_{4}\right],(\mathrm{s}-2, \mathrm{t}-2, \mathrm{u}-2)\left(\mathrm{Et}_{4} \mathrm{~N}\right)_{2}\left[\mathrm{WSe}_{4}\right]$, and $(\mathrm{s}-3, \mathrm{t}-3, \mathrm{u}-3)(\mathrm{CTA})_{2}\left[\mathrm{WSe} \mathrm{H}_{4}\right]$ before and after postannealing at $500{ }^{\circ} \mathrm{C}$ and $600^{\circ} \mathrm{C}$.

homogeneity over large areas except for some small structural imperfections. The chemical characterization of the synthesized $\mathrm{WSe}_{2}$ layers was conducted by XPS. The survey spectrum reveals that $\mathrm{W}, \mathrm{Se}, \mathrm{C}, \mathrm{O}$, and Si-related peaks are observed, which implies the successful formation of $\mathrm{WSe}_{2}$ layers on a $\mathrm{SiO}_{2} / \mathrm{Si}$ substrate, as shown in Fig. 3e. Moreover, the intensity of $\mathrm{C}$ 1s peak decreases significantly after the formation of $\mathrm{WSe}_{2}$ layers, which means that the long alkyl chain of $(\mathrm{CTA})_{2}\left[\mathrm{WSe}_{4}\right]$ is thermally decomposed. Fig. 3f exhibits the $\mathrm{W}$ if core level spectrum extracted from the $\mathrm{WSe}_{2}$ layers on $\mathrm{SiO}_{2} / \mathrm{Si}$, which reveals the successful formation of $\mathrm{WSe}_{2}$ as confirmed by the presence of $\mathrm{W} 4 \mathrm{f}_{7 / 2}$ and $\mathrm{W} 4 \mathrm{f}_{5 / 2}$ bonding states without nonstoichiometric chemical states or oxidation states, which is in good agreement with the Se 3d core level spectrum, as displayed in Fig. 3g. Raman spectra with an excitation wavelength of $514 \mathrm{~nm}$ for the $\mathrm{WSe}_{2}$ layers display degenerated $\mathrm{E}_{2 \mathrm{~g}}$ phonon and $\mathrm{A}_{1 \mathrm{~g}}$ phonon modes prominently, as seen in Fig. 3h. By comparing the Raman spectrum of $\mathrm{WSe}_{2} \mathrm{NPs}$ using (CTA $)_{2}[-$ $\left.\mathrm{WSe}_{4}\right]$, a remarkable decrease in the FWHM of the Raman modes can be adequately explained by the improvement in crystallinity induced by the formation of a two-dimensional structure. Additionally, the crystal structure of $\mathrm{WSe}_{2}$ synthesized by (CTA $)_{2} \mathrm{WSe}_{4}$ was explored by X-ray diffraction (XRD). The XRD patterns of $\mathrm{WSe}_{2}$ were displayed (Fig. S5 $\dagger$ ). The distinct diffraction peaks were located at $13.4,31.8,41.1$, and $55.7^{\circ}$ corresponding to (002), (100), (006), and (008) $2 \mathrm{H}-\mathrm{WSe}_{2}$ crystal planes, respectively, in good agreement with a prior report on the crystal structure of $2 \mathrm{H}-\mathrm{WSe}_{2} \cdot{ }^{28}$ In general, the synthesis of $\mathrm{WSe}_{2}$ by a conventional chemical vapor deposition technique is implemented using co-evaporation of $\mathrm{WO}_{3}$ and Se powder at higher reaction temperatures of $700-900{ }^{\circ} \mathrm{C}^{29-31}$ In this process, the volatile $\mathrm{WO}_{3-x}$ suboxide reduced by injecting $\mathrm{H}_{2}$ is effectively selenized, resulting in the formation of triangular- or hexagonal-shaped $\mathrm{WSe}_{2}$ flakes, which seems to be technically limited for the realization of the device arrays with the same response. We believe that our approach provides a feasible and reliable synthetic route for obtaining homogeneous $\mathrm{WSe}_{2}$ layers through simultaneous conversion of the single source precursor 


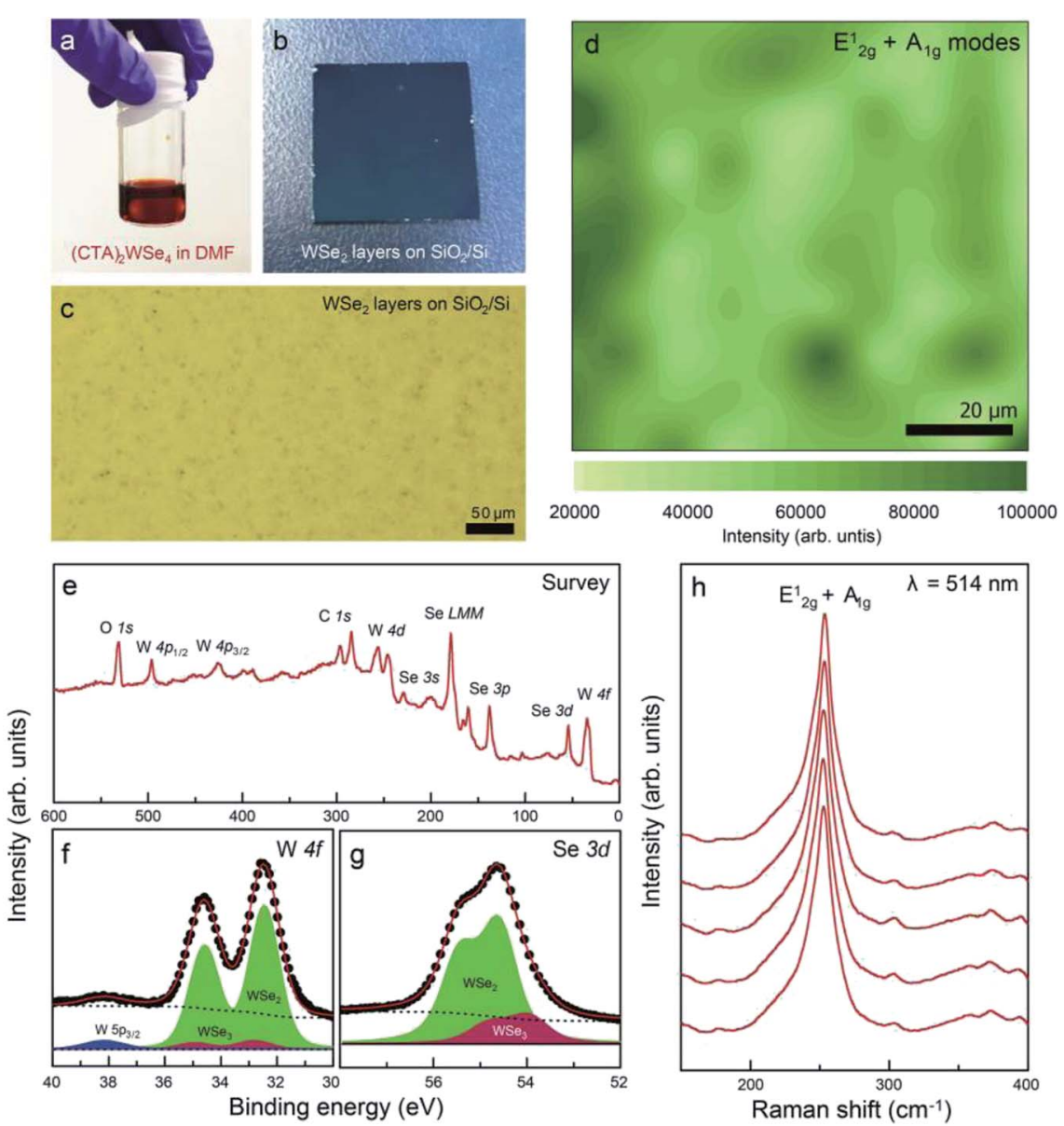

Fig. 3 Photographic images of (a) $0.5 \mathrm{wt} \%(\mathrm{CTA})_{2}\left[\mathrm{WSe}_{4}\right]$ in $\mathrm{DMF}$ and (b) $\mathrm{WSe}_{2}$ layers synthesized on $\mathrm{SiO}_{2}(300 \mathrm{~nm}) / \mathrm{Si}(001)$ using the precursor

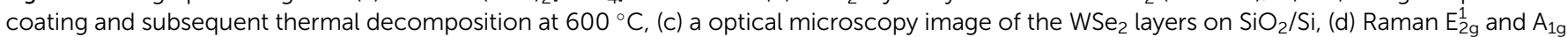
map recorded with an excitation wavelength of $532 \mathrm{~nm}$ for the $\mathrm{WSe}_{2}$ layers on $\mathrm{SiO}_{2} / \mathrm{Si}$, (e) XPS survey, (f) W $4 \mathrm{f}$, and (g) Se $3 \mathrm{~d}$ core level spectra of the $\mathrm{WSe}_{2}$ layers, (h) Raman spectra with an excitation wavelength of $514 \mathrm{~nm}$ for the WSe $\mathrm{W}_{2}$ layers. Each spectrum was taken from different regions of the sample.

at a relatively low temperature. To examine the photoelectrical properties of $\mathrm{WSe}_{2}$ layers synthesized by the two-step thermal decomposition process using $(\mathrm{CTA})_{2} \mathrm{WSe}_{4}$, we fabricated $\mathrm{WSe}_{2}-$ based photodetectors, as illustrated in Fig. 4a. Metal evaporation with a shadow mask was employed to fabricate $100 \mathrm{~nm}$ thick $\mathrm{Au}$ electrodes. The channel length and width corresponded to 10 and $100 \mu \mathrm{m}$, respectively. The infrared (IR,

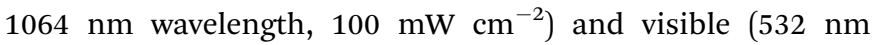
wavelength, $7.2 \mathrm{~mW} \mathrm{~cm}{ }^{-2}$ ) light source were employed for measurement of the photoelectrical properties of the $\mathrm{WSe}_{2}-$ based photodetector. Fig. $4 \mathrm{~b}$ and c display the time-dependent photoconductivity of the $\mathrm{WSe}_{2}$-based photodetector recorded for different bias voltages $(0.1,0.2$, and $0.5 \mathrm{~V})$ using visible and IR light sources and indicate the photocurrent with an abrupt switching behavior under periodic light illumination, regardless of the light sources. Based on these results, the response time $(90 \%$ of the maximum photocurrent) and decay time $(10 \%$ of the minimum photocurrent) at a $0.5 \mathrm{~V}$ bias voltage of the $\mathrm{WSe}_{2}$-based photodetectors using a visible light source were estimated to be 6.8 and $5.6 \mathrm{~s}$, respectively, and the response and decay time of the $\mathrm{WSe}_{2}$-based photodetectors using an IR light source were 5.8 and $7.8 \mathrm{~s}$, which are much greater than those of previously-reported values for solution-processed $\mathrm{MoS}_{2}$-based photodetectors. ${ }^{14}$ These results suggest that the $\mathrm{WSe}_{2}$ layers synthesized using (CTA) ${ }_{2} \mathrm{WSe}_{4}$ may be an appropriate material to realize flexible broadband photodetectors. Fig. 4d shows a linear dependence of the photoresponsivity on the applied voltage for visible and IR light sources, which is the conventional optoelectronic behavior of photoconductors. In general, the photoresponsivity linearly depends on the illumination power or external applied voltage. When the electron-hole pair is formed under the illumination of the light source, the density of photoexcited electrons is proportional to the illumination power, and the Fermi velocity of the electrons contributing to the photocurrent may be influenced by external applied voltages. The extracted photoresponsivity for $\mathrm{WSe}_{2}$-based photodetectors recorded at $0.5 \mathrm{~V}$ corresponds to $26.3 \mathrm{~mA} \mathrm{~W}^{-1}$ for visible light and $5.4 \mathrm{~mA} \mathrm{~W} \mathrm{~W}^{-1}$ for IR light. In addition, electrochemically-gated $\mathrm{WSe}_{2}$-based field effect transistors (FETs) were fabricated to evaluate the carrier transport properties, as depicted in Fig. 4e. The devices contain a top-gate configuration, where $N, N$-diethyl- $N$-methyl- $N$-(2-methoxyethyl) 

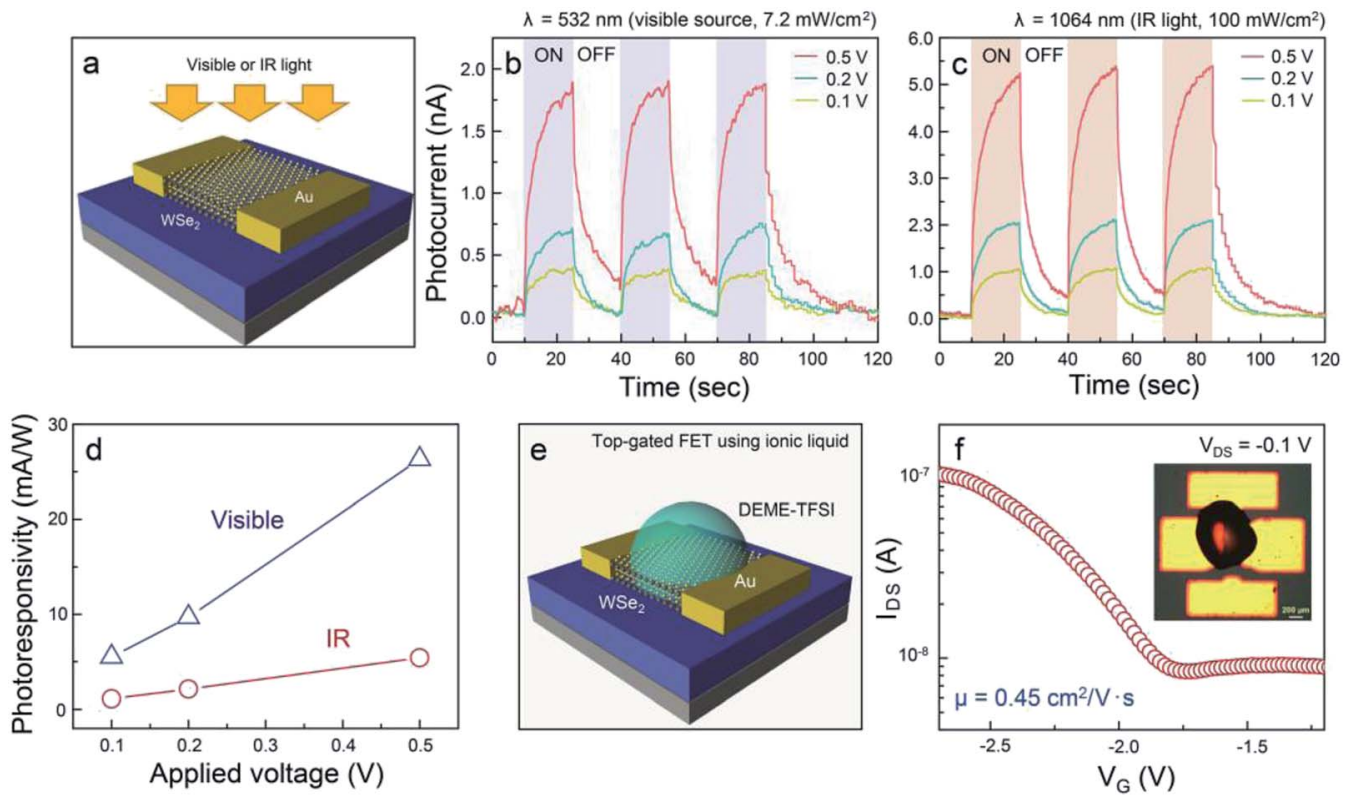

Fig. 4 (a) Schematic of a WSe ${ }_{2}$-based photodetector built on $300 \mathrm{~nm}$-thick $\mathrm{SiO}_{2} / \mathrm{Si}$ with $100 \mathrm{~nm}$-thick Au electrodes, time-dependent photocurrent generated by (b) visible and (c) IR light sources of the WSe $\mathrm{S}_{2}$-based photodetector recorded for different bias voltages $(0.1,0.2$, and $0.5 \mathrm{~V}$ ), (d) the photoresponsivity plots for $\mathrm{WSe}_{2}$-based visible and IR photodetectors as a function of the applied voltage. (e) Schematic depiction of an electrochemically gated WSe $\mathrm{W}_{2}$-based FET. (f) A transfer curve at $V_{\mathrm{DS}}=-1 \mathrm{~V}$ for the $\mathrm{WSe}_{2}$-based FET. Inset indicates an optical microscopy image of the device structure.

ammonium bis(trifluoromethylsulfonyl)imide (DEME-TFSI) and $100 \mathrm{~nm}$-thick Au were used as ionic liquid dielectric and electrodes, respectively. It is widely recognized that DEME-TFSI possesses a large electrochemical stability window ( $>3 \mathrm{~V}$ at room temperature).$^{32}$ It should be noted that TMDs-based FETs with ionic liquid dielectrics provide a crucial route for achieving flexible, high-performance, and low power consumption devices. The channel length and width were 200 and $500 \mu \mathrm{m}$, respectively. Fig. $4 \mathrm{f}$ shows that a representative transfer curve at $V_{\mathrm{DS}}=-0.1 \mathrm{~V}$ for $\mathrm{WSe}_{2}$-based FETs reveals unipolar p-type channel behavior with an on-off current ratio and mobility of 10 and $0.45 \mathrm{~cm}^{2} \mathrm{~V}^{-1} \mathrm{~s}^{-1}$. Since previously-reported $\mathrm{WSe}_{2}$-based FETs have exhibited controversial hole-dominated, ambipolar, and electron-dominated transport behavior, this result paves the way for a universal and effective synthetic methodology for few p-type nanomaterials. ${ }^{33-35}$

\section{Conclusions}

In summary, we proposed two crucial solutions for a promising precursor with high dispersibility and low decomposition temperature and a facile synthetic methodology to produce a large-area p-type $\mathrm{WSe}_{2}$ with spatial homogeneity. In contrast to previously reported $\left(\mathrm{Cat}^{+}\right)_{2}\left[\mathrm{WSe}_{4}\right]$ complexes, a (CTA $)_{2}\left[\mathrm{WSe}_{4}\right]$ precursor with long alkyl chain of cetyltrimethylammonium enables the synthesis of high-crystalline $\mathrm{WSe}_{2}$ layers, as confirmed by XPS and Raman spectroscopy. The optoelectrical and electrical properties of the $\mathrm{WSe}_{2}$-based devices consolidate the possibilities of the newly developed precursor and our synthetic route, which can be used in applications for multifunctional devices, such as complementary logic circuits, gas sensors, and optoelectronic devices.

\section{Conflicts of interest}

There are no conflicts to declare.

\section{Acknowledgements}

This research was supported by a grant (2011-0031636) from the Center for Advanced Soft Electronics under the Global Frontier Research Program of the Ministry of Science, ICT and Future Planning, Korea, and a grant from the development of smart chemical materials for IoT devices project through the Korea Research Institute of Chemical Technology (KRICT) of Republic of Korea (SI1803). We would like to thank the Center for Chemical Analysis at the KRICT for using their facilities for solving the molecular structures.

\section{References}

1 Q. H. Wang, K. K. Zadeh, A. Kis, J. N. Coleman and M. S. Strano, Nat. Nanotechnol., 2012, 7, 699-712.

2 P. Miro, M. Audiffred and T. Heine, Chem. Soc. Rev., 2014, 43, 6537-6554.

3 K. F. Mak, C. Lee, J. Hone, J. Shan and T. F. Heinz, Phys. Rev. Lett., 2010, 105, 136805.

4 S. Ghatak, A. N. Pal and A. Ghosh, ACS Nano, 2011, 5, 77077712.

5 B. Radisavlijevic, M. B. Whitwick and A. Kis, ACS Nano, 2011, 5, 9934-9938. 
6 O. L. Sanchez, D. Lembke, M. Kayci, A. Radenovic and A. Kis, Nat. Nanotechnol., 2013, 8, 497-501.

7 D. J. Late, Y. K. Huang, B. Liu, J. Acharya, S. N. Shirodkar, J. Luo, A. Yan, D. Charles, U. V. Waghmare, V. P. Dravid and C. N. R. Rao, ACS Nano, 2013, 7, 4879-4891.

8 T. Cao, G. Wang, W. Han, H. Ye, C. Zhu, J. Shi, Q. Niu, P. Tan, E. Wang, B. Liu and J. Feng, Nat. Commun., 2012, 3, 887.

9 V. K. Sangwan, H. S. Lee, H. Bergeron, I. Balla, M. E. Beck, K. S. Chen and M. C. Hersam, Nature, 2018, 554, 500.

10 H. Li, J. Wu, Z. Yin and H. Zhang, Acc. Chem. Res., 2014, 47, 1067-1075.

11 M. Chhowalla, H. S. Shin, G. Eda, L. J. Li, K. P. Loh and H. Zhang, Nat. Chem., 2013, 5, 263-275.

12 A. M. V. D. Zande, P. Y. Huang, D. A. Chenet, T. C. Berkelbach, Y. You, G. H. Lee, T. F. Heinz, D. R. Reichman, D. A. Muller and J. C. Hone, Nat. Mater., 2013, 12, 554-561.

13 X. Wang, H. Feng, Y. Wu and L. Jiao, J. Am. Chem. Soc., 2013, 135, 5304-5307.

14 Y. R. Lim, W. Song, J. K. Han, Y. B. Lee, S. J. Kim, S. Myung, S. S. Lee, K. S. An, C. J. Choi and J. Lim, Adv. Mater., 2016, 28, 5025-5030.

15 Y. R. Lim, J. K. Han, S. K. Kim, Y. B. Lee, Y. Yoon, S. J. Kim, B. K. Min, Y. Kim, C. Jeon, S. Won, J. H. Kim, W. Song, S. Myung, S. S. Lee, K. S. An and J. Lim, Adv. Mater., 2018, 30, 1705270.

16 K. Guo, S. Cui, H. Hou, W. Chen and L. Mi, Dalton Trans., 2016, 45, 19458-19465.

17 K. Guo, F. Yang, S. Cui, W. Chen and L. Mi, RSC Adv., 2016, 6, 46523-46530.

18 S. Huang, W. Zhang, S. Cui, W. Chen and L. Mi, Inorg. Chem. Front., 2017, 4, 727-735.

19 W. Wei, L. Mi, S. Cui, B. Wang and W. Chen, ACS Sustainable Chem. Eng., 2015, 3, 2777-2785.

20 H. Fang, S. Chuang, T. C. Chang, K. Takei, T. Takahashi and A. Javey, Nano Lett., 2012, 12, 3788-3792.
21 J. Kang, S. Tongay, J. Zhou, J. Li and J. Wu, Appl. Phys. Lett., 2013, 102, 012111.

22 S. C. O'Neal and J. W. Kolis, J. Am. Chem. Soc., 1988, 110, 1971-1973.

23 Q. Zhang, M. Hong, W. Su, R. Cao and H. Liu, Polyhedron, 1997, 16, 1433-1437.

24 C. Altavilla, M. Sarno and P. Ciambelli, Chem. Mater., 2011, 23, 3879-3885.

25 W. Jung, S. Lee, D. Yoo, S. Jeong, P. Miro, A. Kuc, T. Heine and J. Cheon, J. Am. Chem. Soc., 2015, 137, 7266-7269.

26 Z. Xu, C. Shen, Y. Hou, H. Gao and S. Sun, Chem. Mater., 2009, 21, 1778-1780.

27 A. Mohammed, H. Nakamura, P. Wochner, S. Ibrahimkutty, A. Schulz, K. Muller, U. Starke, B. Stuhlhofer, G. Cristiani, G. Logvenov and H. Takagi, Appl. Phys. Lett., 2017, 111, 073101.

28 J. Wang, D. Rhodes, S. Feng, M. A. T. Nguyen, K. Watanabe, T. Taniguchi, T. E. Mallouk, M. Terrones and J. Zhu, Appl. Phys. Lett., 2015, 106, 152104.

29 J. Chen, B. Liu, Y. Liu, W. Tang, C. T. Nai, L. Li, J. Zheng, L. Gao, Y. Zheng, H. S. Shin, H. Y. Jeong and K. P. Loh, Adv. Mater., 2015, 27, 6722-6727.

30 J. Huang, L. Yang, D. Liu, J. Chen, Q. Fu, Y. Xiong, F. Lin and B. Xiang, Nanoscale, 2015, 7, 4193.

31 B. Liu, M. Fathi, L. Chen, A. Abbas, Y. Ma and C. Zhou, ACS Nano, 2015, 9, 6119-6127.

32 M. M. Perera, M. W. Lin, H. J. Chuang, B. P. Chamlagain, C. Wang, X. Tan, M. M. C. Cheng, D. Tomanek and Z. Zhou, ACS Nano, 2013, 7, 4449-4458.

33 H. Zhou, C. Wang, J. C. Shaw, R. Cheng, Y. Chen, X. Huang, Y. Liu, N. O. Weiss, Z. Lin, Y. Huang and X. Duan, Nano Lett., 2015, 15, 709-713.

34 W. Liu, J. Kang, D. Sarkar, Y. Khatami, D. Jena and K. Banerjee, Nano Lett., 2013, 13, 1983-1990.

35 S. Das and J. Appenzeller, Appl. Phys. Lett., 2013, 103, 103501. 